\title{
Concentração no mercado mundial de arroz: Algumas evidências empíricas
}

\author{
Alcido Elenor Wander \\ Pesquisador da Empresa Brasileira de Pesquisa Agropecuária (Embrapa) - Santo Antônio \\ de Goiás (GO) e Docente do Centro Universitário Alves Faria (UNIALFA) - Goiânia (GO). \\ Email: alcido.wander@embrapa.br
}

Cleyzer Adrian da Cunha

Programa de Pós-Graduação em Economia - PPE/FACE/UFG.

Email: cleyzercunha@gmail.com

Resumo: O presente trabalho visou determinar o grau de concentração do mercado internacional de arroz. Foram utilizadas as seguintes variáveis: (a) Quantidade (t) de arroz exportada por país, e (b) Quantidade (t) de arroz importada por país. Foram determinados os seguintes índices de concentração: (a) razão de concentração $C R(k)$; (b) quartéis de concentração; e (c) Índice de Herfindahl-Hirschman (IHH). Além disso, os países foram agrupados em clusters de exportadores e importadores, considerando as quantidades exportadas/importadas em 2012. Os resultados apontam que o mercado internacional de arroz é pouco concentrado, porém com tendência ao aumento de concentração. As exportações de arroz são mais concentradas em poucos países, do que as importações. Os maiores exportadores são asiáticos (Tailândia, Vietnã, Índia e Paquistão) e os Estados Unidos da América. Os maiores importadores são asiáticos (China, Indonésia e Filipinas), africanos (Nigéria, Costa do Marfim, Senegal e África do Sul) e do Oriente Médio (Iraque, Arábia Saudita e Irã).

Palavras-chave: razão de concentração; quartéis de concentração; Índice de HerfindahlHirschman

Abstract: This study aimed to determine the degree of concentration of the international rice market. The following variables were used: (a) Amount of rice exported by country, and (b) Amount of rice imported by country. The following concentration indices were determined: (a) concentration ratio CR ( $k$ ); (b) concentration quarters; and (c) HerfindahlHirschman Index (HHI). In addition, countries were grouped in clusters of exporters and importers, considering the quantities exported / imported in 2012. The results show that the international market for rice is of low concentration, but with a tendency to increase its density. Rice exports are more concentrated in a few countries than imports. The largest exporters are in Asia (Thailand, Vietnam, India and Pakistan) and the United States of America. The main importers are in Asia (China, Indonesia and the Philippines), Africa (Nigeria, Ivory Coast, Senegal and South Africa) and the Middle East (Iraq, Saudi Arabia and Iran).

Key words: concentration ratio; concentration quarter; Herfindahl-Hirschman Index JEL Code: Q11, Q12, Q13 
p. 3 - Concentração no mercado mundial de arroz: Algumas evidências empíricas

\section{INTRODUÇÃO}

As estruturas de mercado descrevem os mercados e seus componentes, definindo a capacidade e a possibilidade de se operar seus componentes em concorrência ou não no mercado. O estudo das formas de mercado avalia o tamanho e a capacidade que tem uma empresa para deter poder de mercado e definir o preço de um produto homogêneo. Às vezes as condições para a deter poder de mercado são restritas, existindo muito poucos mercados com o pleno poder. Portanto algumas estruturas podem servir somente como ponto de referência para avaliar outros mercados no mundo real.

As formas de mercado mais conhecidas são: (a) a concorrência monopolística (mercado competitivo), onde há um grande número de players, cada um com uma pequena proporção da participação de mercado e produtos ligeiramente diferenciados; (b) o oligopólio, em que um mercado é dominado por um pequeno número de players que, juntos, controlam a maioria da quota de mercado; (c) o duopólio, um caso especial de um oligopólio com dois players; (d) o oligopsônio, um mercado, onde muitos vendedores podem estar presentes, mas encontram poucos compradores; (e) o monopólio, onde existe apenas um fornecedor de um produto ou serviço; (f) o monopólio natural, um monopólio em que economias de escala para aumentar a eficiência causam continuamente com o tamanho do player (um player um monopólio natural se ele é capaz de servir toda a demanda do mercado a um custo menor do que qualquer combinação de dois ou mais players menores e mais especializados); (g) o monopsônio, quando há apenas um comprador no mercado; e (h) a concorrência perfeita, que é uma estrutura de mercado teórica que descreve mercados em que nenhum participante tem tamanho suficiente para ter o poder de mercado para definir o preço de um produto homogêneo (STIGLITZ, 1997).

Helpman e Krugman (1985) apresentaram e definiram as teorias de comércio na presença de outras estruturas de mercado que não a concorrência perfeita. No início da década de 1990, Cramer et al. (1993) já previam o aumento considerável das quantidades transacionadas e preços do arroz no mercado mundial. Previam também que países como Japão, Coréia do Sul, Filipinas, Taiwan e Brasil se tornariam os principais importadores de arroz. Esperava-se um forte aumento das exportações dos Estados Unidos da América.

Fernandes et al. (2008) avaliaram a competitividade do arroz brasileiro frente ao mercado mundial. Esta competitividade também foi estudada por Wander (2006), que demonstrou relativa desvantagem do arroz brasileiro perante outros players do Mercosul.

Por outro lado, o Brasil continuou importando quantidades expressivas de arroz, mesmo após ter se tornado autossuficiente. Capitani e Miranda (2011) avaliaram a demanda brasileira por importação de arroz do Mercosul.

Após a crise alimentar de 2007-2008, diversos países criaram restrições às exportações de arroz, visando assegurar o abastecimento interno (MARTIN; ANDERSON, 2011). 
O mercado mundial do arroz apresenta indícios de concorrência imperfeita. Em economia, concentração de mercado, ou concentração no ramo de atividade (exportação de arroz), é uma função do número de players e das suas respectivas quotas de mercado no total das vendas num mercado (ex. mercado mundial de arroz) (OECD, 2003).

Este trabalho é relevante, no estudo do comércio internacional, uma vez que inexistem estudos assim e, como o Brasil se tornou autossuficiente na produção de arroz em 2003, é importante conhecer o ambiente competitivo que o país está adentrando desde então. Assim, o presente trabalho visa determinar o grau de concentração do mercado internacional de arroz.

\section{METODOLOGIA}

\subsection{Variáveis utilizadas}

As variáveis utilizadas foram: (a) Quantidade (t) de arroz exportada por país, e (b) Quantidade (t) de arroz importada por país. A China foi considerada em seu conjunto, incluindo Hong Kong, Macao e Taiwan.

\subsection{Fonte de dados}

O período de dados considerados foi de 2000 a 2012 (último ano de dados disponíveis). Foram selecionados para análise os anos de 2000, 2005, 2010 e 2012. Os dados foram obtidos da base de dados Faostat (FAO, 2015).

\subsection{Indicadores de concentração utilizados}

Para analisar a concentração do mercado internacional de arroz, utilizaram-se índices que avaliam o grau de concorrência nos mercados. Entre os índices de concentração, optou-se pela razão de concentração $C R(k)$, método dos quartéis de concentração e o Índice de Herfindahl-Hirschman (IHH). Além disso, os países foram agrupados em clusters de exportadores e importadores, considerando as quantidades exportadas/importadas em 2012.

A razão de concentração $C R(k)$ permite quantificar a participação percentual de mercado de $k$ players (países, no caso). Primeiramente os países participantes foram ranqueados em ordem decrescente, segundo a quantidade e o valor de importações e exportações. Em seguida, foram acumulados os percentuais até chegar no número de países que se pretendia considerar. Neste estudo, foram considerados CR2, CR5 e CR10, representando, respectivamente, os dois, os cinco e os dez maiores exportadores ou importadores de arroz.

O método dos Quartéis de concentração foi implementado conforme descrito em Wander (2011). Os países foram ordenados em ordem decrescente para as variáveis (a) Quantidade (t) de arroz exportada por país, e (b) Quantidade (t) de arroz importada por país, em cada um dos anos de estudo (2000, 2005, 2010 e 2012). Com isso, foi possível identificar os principais países exportadores e importadores de arroz. 
p. 5 - Concentração no mercado mundial de arroz: Algumas evidências empíricas

A metodologia utilizada para que houvesse a distinção entre os países exportadores e importadores, foi o método dos Quartéis ${ }^{1}$ : o quartel superior (Q4) é formado pelo menor conjunto de países exportadores/importadores que respeitam o ordenamento e são suficientes para alcançar pelo menos $25 \%$ das exportações/importações de arroz; o terceiro quartel (Q3) é formado pelos países seguintes, até que consiga alcançar em conjunto com o Q4 50\% das exportações/importações; os outros países seguem a mesma lógica, com Q4 e Q3 em grupo até formar 75\% das exportações/importações perfazendo o Q2 e os países restantes formando o quartel inferior que é o Q1 (WANDER, 2011).

Ressalta-se que como são países e que pode haver oscilações quanto às exportações e importações e a participação dos mesmos e até mudanças dos países que mais exportavam/importavam, não é possível garantir que um quartel terá $25 \%$ das exportações/importações, podendo acontecer que Q4 reúna 34,56\% das exportações/importações, ou que Q3 reúna 62,90\% das exportações/importações. A técnica utilizada apenas garante que se tenha o mínimo de países possíveis para que possa determinar a porcentagem (25, 50 e 75\%), incluindo o país que se sobressaiu e os outros abaixo dele, para que se forme o Quartel e a análise possa ser utilizada (WANDER, 2011).

Já o Índice de Herfindahl-Hirschman (IHH) foi definido para mensurar a concentração de mercado. É calculado a partir da soma dos quadrados da fatia de mercado de cada player $\left(P_{i j}\right)$, em relação ao tamanho total do mercado (SANTOS; SANTANA, 2003; ELMAS; DEGIRMEN, 2009), conforme a Equação 1.

$$
\mathrm{HH}=i=1 n P_{i 2}
$$

O IHH pode variar de 0 a 10.000, com os extremos representando concorrência perfeita e monopólio, respectivamente. Os players com maior market share participam com maior peso na formação do índice, pois ao se elevar ao quadrado o market share, o IHH atribui maior peso aos players de maior expressão (SANTOS; SANTANA, 2003). Desse modo, quando existe uniformidade entre os players de um setor, ou quando o número de players se eleva, o IHH diminui. Nessa perspectiva, Santos e Santana (2003) assumem que valores inferiores a 1.000 indicam ausência de concentração; entre 1.000 e 1.800, a concentração é considerada baixa e a cima de 1.800, a concentração é considerada alta.

Para agrupar os países exportadores e importadores de arroz em clusters foi utilizado o software Philcarto para Windows (WANIEZ, 2014). Utilizou-se a classificação "Jenks", com 4 classes.

\footnotetext{
${ }^{1}$ Conforme o Dicionário Eletrônico Aurélio versão 5.0 (2005): "6. Estat. Numa distribuição de frequência, conjunto de valores compreendidos entre dois quartis consecutivos.". O Quartil é o ponto, enquanto que o Quartel é o intervalo entre os pontos (quartis).
} 


\section{RESULTADOS E DISCUSSÃO}

\subsection{Exportações de arroz}

Entre as razões de concentração consideradas, apenas na CR2 foi possível observar uma tendência de aumento da concentração relativa dos dois principais países exportadores, principalmente considerando o período 2000 a 2010. Neste período, a Tailândia e o Vietnã ampliaram sua participação nas exportações de arroz de $36 \%$ em 2000 para $46 \%$ em 2010 (

Tabela 1). No último ano estudado chama a atenção a entrada da Índia para este grupo dos 2 maiores exportadores de arroz. Trata-se de uma situação excepcional, considerando que Tailândia e Vietnã são, tradicionalmente, os dois maiores exportadores de arroz.

Tabela 1: Razões de concentração (CR2, CR5 e CR10) e Índice de Herfindahl-Hirschman (IHH) das exportações de arroz dos países, 2000 a 2012, anos selecionados.

\begin{tabular}{|c|c|c|c|c|c|c|c|c|}
\hline \multirow[t]{2}{*}{ Indicador } & \multicolumn{2}{|c|}{2000} & \multicolumn{2}{|c|}{2005} & \multicolumn{2}{|c|}{2010} & \multicolumn{2}{|c|}{2012} \\
\hline & Indicador & Países & Indicador & Países & Indicador & Países & Indicador & Países \\
\hline CR2 & $36,31 \%$ & $\begin{array}{l}\text { Tailândia } \\
\text { Vietnã }\end{array}$ & $42,44 \%$ & $\begin{array}{l}\text { Tailândia } \\
\text { Vietnã }\end{array}$ & $46,16 \%$ & $\begin{array}{l}\text { Tailândia } \\
\text { Vietnã }\end{array}$ & $46,14 \%$ & $\begin{array}{l}\text { Índia } \\
\text { Vietnã }\end{array}$ \\
\hline CR5 & $76,75 \%$ & $\begin{array}{l}\text { CR2 + } \\
\text { China } \\
\text { EUA } \\
\text { Paquistão }\end{array}$ & $78,17 \%$ & $\begin{array}{l}\text { CR2 + } \\
\text { Índia } \\
\text { EUA } \\
\text { Paquistão }\end{array}$ & $75,82 \%$ & $\begin{array}{l}\text { CR2 + } \\
\text { Paquistão } \\
\text { EUA } \\
\text { Índia }\end{array}$ & $79,53 \%$ & $\begin{array}{l}\text { CR2 + } \\
\text { Tailândia } \\
\text { Paquistão } \\
\text { EUA }\end{array}$ \\
\hline CR10 & $91,83 \%$ & $\begin{array}{l}\text { CR5 + } \\
\text { Índia } \\
\text { Uruguai } \\
\text { Itália } \\
\text { Austrália } \\
\text { Argentina }\end{array}$ & $91,12 \%$ & $\begin{array}{l}\text { CR5 + } \\
\text { Egito } \\
\text { Itália } \\
\text { Uruguai } \\
\text { China } \\
\text { Argentina }\end{array}$ & $85,72 \%$ & $\begin{array}{l}\text { CR5 + } \\
\text { Itália } \\
\text { Uruguai } \\
\text { China } \\
\text { Egito } \\
\text { Em. Ár. } \\
\text { Unidos }\end{array}$ & $89,34 \%$ & $\begin{array}{l}\text { CR5 + } \\
\text { Brasil } \\
\text { Uruguai } \\
\text { Itália } \\
\text { Argentina } \\
\text { Myanmar }\end{array}$ \\
\hline $\mathrm{IHH}$ & 9,22 & - & 10,02 & - & 10,35 & - & 10,84 & - \\
\hline
\end{tabular}

Fonte: Dados da pesquisa.

Considerando-se o grupo dos 5 maiores exportadores (CR5), nota-se que países como EUA e Paquistão surgem como exportadores consistentes. Quatro dos cinco maiores exportadores são asiáticos. Este grupo responde por 75 a $80 \%$ das exportações de arroz. Não foi possível identificar uma tendência na participação destes países nas exportações totais.

Expandindo-se para o grupo dos 10 maiores exportadores (CR10), tem-se 85 a 92\% das exportações de arroz. Também não é possível identificar uma tendência na participação destes países no total das exportações. Neste grupo somam-se países como Itália, Myanmar e países do Mercosul (Uruguai, Argentina e Brasil). Interessante observar que os Emirados Árabes Unidos estavam neste grupo, apesar de não serem produtores de arroz, ou seja, este país importa e reexporta arroz.

Portanto, segundo as razões $\mathrm{CR}(\mathrm{k})$ existe relativa concentração das exportações de arroz. 
Já o Índice Herfindahl-Hirschman (IHH) mostra uma tendência consistente de aumento $(9,22$ para 10,84), mas ainda está em níveis inferiores a 1.000, o que indica a ausência de concentração no mercado exportador.

Considerando os Quartéis de Concentração das exportações (Tabela 2), nota-se um aumento do número de países que exportam arroz e uma diminuição do número de países responsáveis por pelo menos $25 \%$ das exportações (Q4), que passaram a compor o grupo que responde por até 50\% (Q3). Em linhas gerais, tem-se um grupo de 5 países que responde por pelo menos $75 \%$ das exportações de arroz (Tabela 2).

Tabela 2: Distribuição dos países exportadores de arroz em quartéis de concentração, ordenados em ordem decrescente de quantidade exportada, 2000, 2005, 2010 e 2012.

\begin{tabular}{llllll}
\hline Ano & \multicolumn{5}{c}{ Número de países } \\
\cline { 2 - 6 } & Q1 & Q2 & Q3 & Q4 & Total \\
\hline 2000 & 124 & 2 & 1 & 2 & 129 \\
2005 & 135 & 2 & 1 & 2 & 140 \\
2010 & 133 & 2 & 2 & 1 & 138 \\
2012 & 136 & 2 & 2 & 1 & 141 \\
\hline
\end{tabular}

Fonte: Dados da pesquisa.

Os países responsáveis por pelo menos 25\% das exportações (Q4) em 2000 e 2005 vinham sendo Tailândia e Vietnã. Em 2010 a Tailândia aumentou suas exportações a ponto de responder, sozinha, por mais de 25\% das exportações de arroz. Já em 2012 a Índia surgiu como maior exportadora, tendo sido responsável por mais de $25 \%$ das exportações daquele ano (Tabela 3).

Tabela 3: Países responsáveis por pelo menos 25\% das exportações de arroz (Q4), 2000, 2005, 2010 e 2012.

\begin{tabular}{llll}
\hline 2000 & 2005 & 2010 & 2012 \\
\hline $\begin{array}{l}\text { Tailândia } \\
\text { Vietnã }\end{array}$ & Tailândia & Tailândia & Índia \\
\hline
\end{tabular}

Fonte: Dados da pesquisa.

A Figura 1 mostra os países exportadores de arroz agrupados em 4 clusters, segundo a quantidade exportada em 2012. Fica evidente a concentração dos maiores exportadores no continente asiático. Os EUA representam uma exceção neste aspecto. 


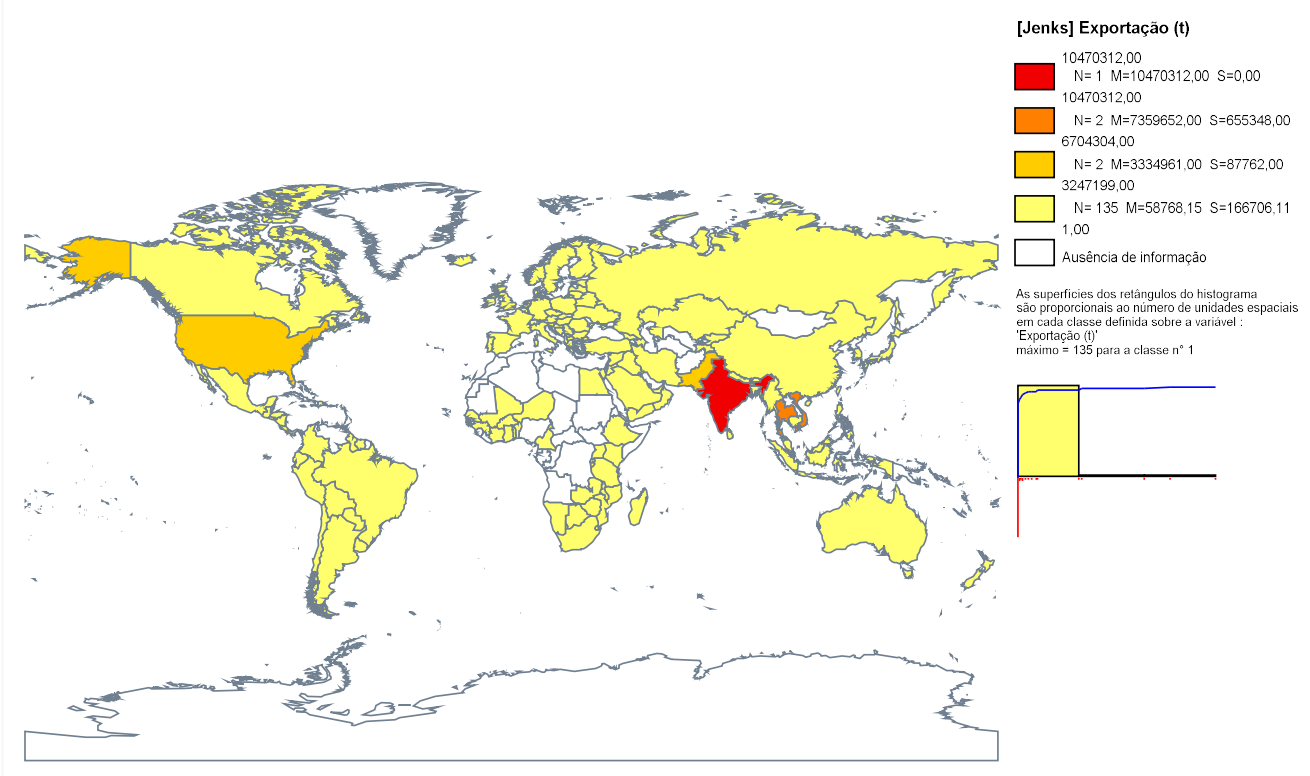

Paises exportadores de arroz (t, 2012)
Elaborado com Philcarto * 25/10/2015 $18: 43: 42 *$ htp:l/lphicarto.free.fi

Figura 1: Clusters dos países exportadores de arroz, em quantidade, em 2012 Fonte: Elaboração própria a partir de dados da FAO (2015).

O número total de países exportadores tem aumentado. No entanto, tem havido uma concentração entre os maiores exportadores, que tem aumentado sua participação nas exportações totais de arroz.

Trata-se, portanto, de um mercado de concorrência imperfeita (STIGLITZ, 1997), onde a concentração de mercado (OECD, 2003) não é acentuada, mas tem aumentado, apesar de o número total de países exportadores ter apresentado crescimento.

\subsection{Importações de arroz}

Considerando as razões de concentração das importações de arroz pelos países nota-se, primeiro, que a participação dos diferentes grupos $(C R(k))$ é bem menor do que nas exportações (Tabela 4). Percebe-se, também, que os 3 grupos (CR2, CR5 e CR10) tiveram uma ligeira queda de suas participações de 2000 a 2005. De 2005 a 2012, os 3 grupos aumentaram sua participação. Este fato possui relação com uma superoferta mundial ocorrida naquele ano, fazendo com que houvesse uma maior participação dos pequenos importadores, já que os preços estavam mais baixos naquele ano.

Assim, a análise das importações se torna mais consistente de 2005 a 2012. Neste período os 2 maiores importadores (CR2) ampliaram sua participação nas importações mundiais de 10 para 18\%. A Nigéria representa o país que mais figura entre os 2 maiores importadores de arroz. Expandindo-se para o grupo dos 5 maiores exportadores (CR5), estes também ampliaram sua participação no período, passando de 21 para 30\%. Entre os 5 maiores importadores tem-se, também, países como Arábia Saudita e Irã, e outros, 
p. 9 - Concentração no mercado mundial de arroz: Algumas evidências empíricas

em anos isolados. Expandindo-se ainda mais para os 10 maiores importadores (CR10) nota-se uma diversidade de países e continentes, que apresentam variações ao longo dos anos. Nota-se, contudo, que os grandes importadores estão na Ásia, no Oriente Médio, na África e o Brasil, na América do Sul. Chama a atenção que países como o Brasil e os Emirados Árabes Unidos se destacam, tanto como exportadores, como também como importadores (Tabela 4).

Tabela 4: Razões de concentração (CR2, CR5 e CR10) e Índice de Herfindahl-Hirschman (IHH) das importações de arroz dos países, 2000 a 2012, anos selecionados.

\begin{tabular}{|c|c|c|c|c|c|c|c|c|}
\hline \multirow[t]{2}{*}{ Indicador } & \multicolumn{2}{|c|}{2000} & \multicolumn{2}{|c|}{2005} & \multicolumn{2}{|c|}{2010} & \multicolumn{2}{|c|}{2012} \\
\hline & Indic. & Países & Indic. & Países & Indic. & Países & Indic. & Países \\
\hline CR2 & $11,00 \%$ & $\begin{array}{l}\text { Indonésia } \\
\text { Iraque }\end{array}$ & $10,39 \%$ & $\begin{array}{l}\text { Filipinas } \\
\text { Nigéria }\end{array}$ & $13,01 \%$ & $\begin{array}{l}\text { Filipinas } \\
\text { Nigéria }\end{array}$ & $18,36 \%$ & $\begin{array}{l}\text { China } \\
\text { Nigéria }\end{array}$ \\
\hline CR5 & $22,87 \%$ & $\begin{array}{l}\text { CR2 + } \\
\text { Irã } \\
\text { Aráb. } \\
\text { Saudita } \\
\text { Nigéria }\end{array}$ & $21,41 \%$ & $\begin{array}{l}\text { CR2 + } \\
\text { Irã } \\
\text { Aráb. } \\
\text { Saudita } \\
\text { China }\end{array}$ & $24,86 \%$ & $\begin{array}{l}\text { CR2 + } \\
\text { Em. Ár. } \\
\text { Unidos } \\
\text { Aráb. } \\
\text { Saudita } \\
\text { Irã }\end{array}$ & $30,39 \%$ & $\begin{array}{l}\text { CR2 + } \\
\text { Indonésia } \\
\text { C. do } \\
\text { Marfim } \\
\text { Iraque }\end{array}$ \\
\hline CR10 & $37,15 \%$ & $\begin{array}{l}\text { CR5 + } \\
\text { Cor. do } \\
\text { Norte } \\
\text { Japão } \\
\text { Filipinas } \\
\text { Brasil } \\
\text { Malásia }\end{array}$ & $35,55 \%$ & $\begin{array}{l}\text { CR5 + } \\
\text { Senegal } \\
\text { Iraque } \\
\text { C. do } \\
\text { Marfim } \\
\text { Cor. do } \\
\text { Norte } \\
\text { Japão }\end{array}$ & $38,72 \%$ & $\begin{array}{l}\text { CR5 + } \\
\text { Iraque } \\
\text { Malásia } \\
\text { China } \\
\text { C. do } \\
\text { Marfim } \\
\text { Brasil }\end{array}$ & $44,19 \%$ & $\begin{array}{l}\text { CR5 + } \\
\text { África do } \\
\text { Sul } \\
\text { Aráb. } \\
\text { Saudita } \\
\text { Senegal } \\
\text { Irã } \\
\text { Filipinas }\end{array}$ \\
\hline $\mathrm{IHH}$ & 1,08 & - & 1,04 & - & 1,17 & - & 1,26 & - \\
\hline
\end{tabular}

Fonte: Dados da pesquisa.

No caso dos Emirados Árabes Unidos, que não produzem arroz, boa parte das importações são reexportadas. No caso do Brasil, que é o maior produtor de arroz fora do continente asiático, importa-se arroz em volumes expressivos para cumprir acordos comerciais, principalmente com países do Mercosul (Uruguai e Argentina) ou para suprir tipos de grãos de arroz que são consumidos no Brasil, mas cuja produção acontece em outros países da Europa (Itália) e Ásia.

Já o Índice Herfindahl-Hirschman (IHH) mostra uma tendência de aumento a partir de 2005 (1,04 para 1,26), mas ainda está em níveis muito inferiores a 1.000, o que indica a ausência de concentração no mercado importador.

Os Quartéis de Concentração das importações de arroz (Tabela 5) demonstram que houve uma diminuição consistente do número de países que respondiam por pelo menos 25 e 50\% das importações de arroz. Isso reforça a ideia de que os principais importadores aumentaram sua participação no total das importações de arroz no período analisado. 
Tabela 5: Distribuição dos países importadores de arroz em quartéis de concentração, ordenados em ordem decrescente de quantidade importada, 2000, 2005, 2010 e 2012.

\begin{tabular}{llllll}
\hline Ano & \multicolumn{5}{c}{ Número de países } \\
\cline { 2 - 6 } & Q1 & Q2 & Q3 & Q4 & Total \\
\hline 2000 & 157 & 20 & 12 & 6 & 195 \\
2005 & 162 & 20 & 10 & 7 & 199 \\
2010 & 165 & 20 & 10 & 6 & 201 \\
2012 & 163 & 21 & 9 & 4 & 197 \\
\hline
\end{tabular}

Fonte: Dados da pesquisa.

Enquanto que em 2000, eram necessários 6 países para se acumular pelo menos 25\% das importações, em 2012 bastavam 4 países. Nigéria se destaca como único país presente entre os maiores importadores em todos os anos considerados. Até 2010 havia vários países do Oriente Médio (Emirados Árabes Unidos, Arábia Saudita, Irã e Iraque) entre estes países maiores importadores de arroz. Já em 2012 os maiores importadores estavam todos na Ásia e na África (Tabela 6).

Tabela 6: Países responsáveis por pelo menos 25\% das importações de arroz (Q4), 2000, 2005, 2010 e 2012.

\begin{tabular}{llll}
\hline \multicolumn{1}{c}{2000} & \multicolumn{1}{c}{2005} & \multicolumn{1}{c}{2010} & \multicolumn{1}{c}{2012} \\
\hline Indonésia & Filipinas & Filipinas & China \\
Iraque & Nigéria & Nigéria & Nigéria \\
Irã & Irã & Emirados Árabes & Indonésia \\
Arábia Saudita & Arábia Saudita & Unidos & Costa do Marfim \\
Nigéria & China & Arábia Saudita & \\
Coréia do Norte & Senegal & Irã & \\
& Iraque & Iraque & \\
\hline
\end{tabular}

Fonte: Dados da pesquisa.

A Figura 2 apresenta os 4 clusters dos países importadores de arroz, agrupados pela quantidade importada em 2012. Os clusters 1 e 2 (maiores importadores) estão localizados na Ásia, África e Oriente Médio. 


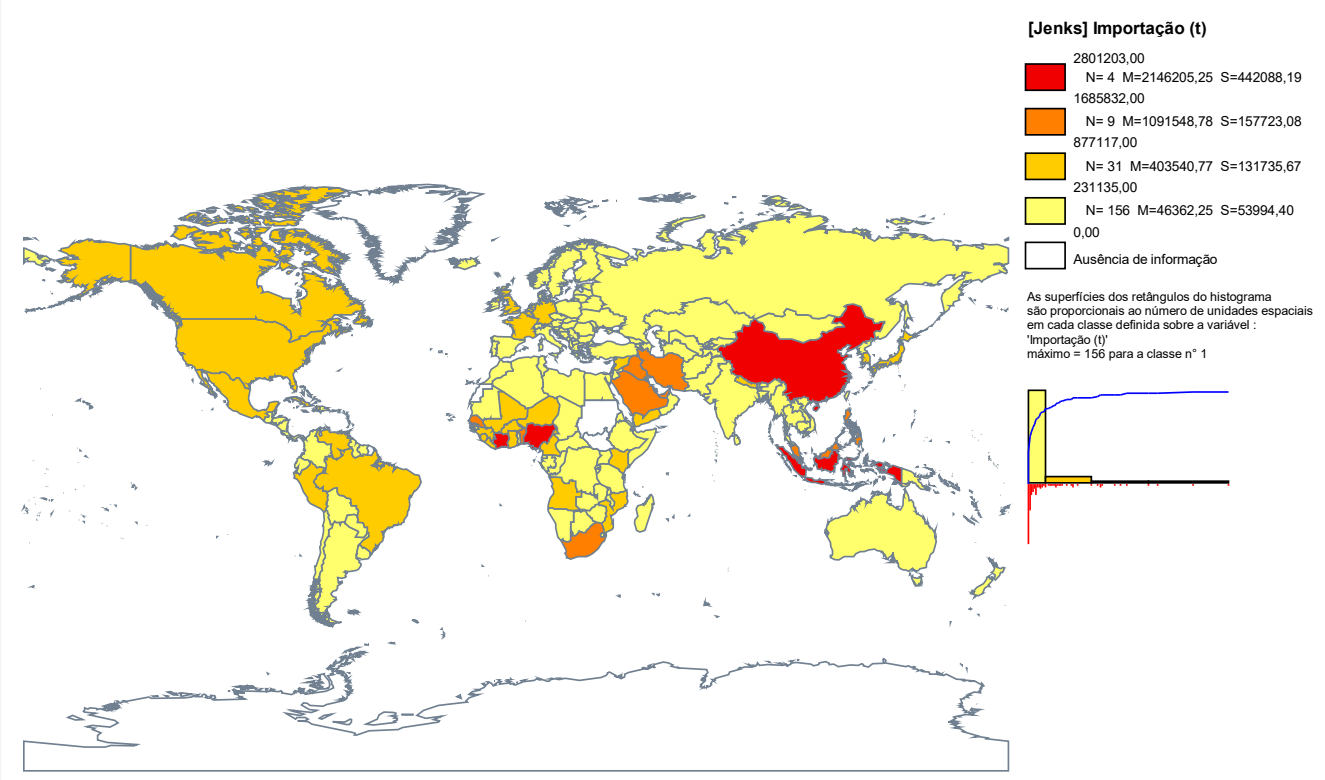

Paises importadores de arroz (t, 2012 )
Elaborado com Philcarto * 25/10/2015 19:14:25 * http://philcarto.free.fr

Figura 2: Clusters dos países importadores de arroz, em quantidade, em 2012 Fonte: Elaboração própria a partir de dados da FAO (2015).

Considerando o conjunto de países importadores e sua participação, nota-se que as importações são menos concentradas do que as exportações.

\section{CONCLUSÕES}

O mercado internacional de arroz apresenta-se pouco concentrado, porém com tendência ao aumento de concentração.

As exportações de arroz são mais concentradas em poucos países, do que as importações.

Os maiores exportadores são asiáticos (Tailândia, Vietnã, Índia e Paquistão) e os EUA. Os maiores importadores são asiáticos (China, Indonésia e Filipinas), africanos (Nigéria, Costa do Marfim, Senegal e África do Sul) e do Oriente Médio (Iraque, Arábia Saudita e Irã).

\section{REFERÊNCIAS}

CAPITANI, D.H.D.; MIRANDA, S.H.G. Determinantes da demanda brasileira por importação de arroz do Mercosul. Revista de Economia e Sociologia Rural, Brasília, v.49, n.3, p. 545-572, 2011.

CRAMER, G.L.; WAILES, E.J.; SHUI, S. Impacts of liberalizing trade in the world rice market. American Journal of Agricultural Economics, v.75, n.1, p.219-226, 1993. 
ELMAS, F.; DEGIRMEN, S. Foreign Direct Investment and Industrial Concentration in the Turkish Manufacturing System. International Research Journal of Finance and Economics, v.23, n.1, p.246-252, 2009.

FAO. Base de dados FAOSTAT. Disponível em: <http://faostat.fao.org>. Acesso em: 24 mai. 2015.

FERNANDES, S. de M.; WANDER, A.E.; FERREIRA, C.M. Análise da competitividade do arroz brasileiro: vantagem comparativa revelada. In: 46 Congresso da SOBER, 20 a 23 de julho de, 2008, Rio Branco, Acre, Brasil. Sociedade Brasileira de Economia, Administração e Sociologia Rural (SOBER), 2008.

HELPMAN, E.; KRUGMAN, P.R. Market structure and foreign trade: Increasing returns, imperfect competition, and the international economy. MIT press, 1985.

MARTIN, W.; ANDERSON, K. Export restrictions and price insulation during commodity price booms. American Journal of Agricultural Economics, p. aar105, 2011.

OECD. Concentration. In: Glossary of statistic terms. 2003. Disponível em: <http://stats.oecd.org/glossary/detail.asp?ID=3165>. Acesso em: 04 abr. 2018.

SANTOS, M.A.S.; SANTANA, A.C. de. Análise da competitividade das micro e pequenas empresas de artefatos de madeira do Estado do Pará. Revista do IESAM, Belém, v.1, p.257-269, jun. 2003.

STIGLITZ, J.E. Microeconomics. New York, NY: WW Norton, 1997.

WANDER, A.E. A competitividade do agronegócio brasileiro de arroz. Custos e Agronegócio online, Recife, v.2, n.1, 2006, p.1-14.

WANDER, A.E. Padrões de concentração das cinco principais atividades do agronegócio do Centro-Oeste. In: CALADO, L.R.; COSTA FILHO, B.A. da; CARVALHO FILHO, N.; OLIVEIRA, R.D. Temas em Administração. Volume 1. Vila Velha-ES: Opção Editora. 2011. p.27-38.

WANIEZ, P. Software Philcarto para Windows. Versão 5.75. 15/12/2014.

\section{AGRADECIMENTO}

Os autores agradecem ao Centro de Pesquisa em Desenvolvimento Regional (CPDR) do Centro Universitário Alves Faria (UNIALFA) pelo auxílio recebido no período de março a agosto de 2015 para a realização desta pesquisa. 